Article

\title{
Vibration Suppression of Wind/Traffic/Bridge Coupled System Using Multiple Pounding Tuned Mass Dampers (MPTMD)
}

\author{
Xinfeng Yin ${ }^{1}$ *, Gangbing Song ${ }^{2}$ and Yang Liu ${ }^{1}$ \\ 1 School of Civil Engineering, Changsha University of Science \& Technology, Changsha 410114, China; \\ liuyangbridge@163.com \\ 2 Department of Mechanical Engineering, University of Houston, Houston, TX 77204, USA; \\ gsong@central.uh.edu \\ * Correspondence: yinxinfeng@163.com
}

Received: 5 January 2019; Accepted: 23 February 2019; Published: 6 March 2019

\begin{abstract}
Dynamic responses of highway bridges induced by wind and stochastic traffic loads usually exceed anticipated values, and tuned mass dampers (TMDs) have been extensively applied to suppress dynamic responses of bridge structures. In this study, a new type of TMD system named pounding tuned mass damper (PTMD) was designed with a combination of a tuned mass and a viscoelastic layer covered delimiter for impact energy dissipation. Comprehensive numerical simulations of the wind/traffic/bridge coupled system with multiple PTMDs (MPTMDs) were performed. The coupled equations were established by combining the equations of motion of both the bridge and vehicles in traffic. For the purpose of comparing the suppressing effectiveness, the parameter study of the different numbers and locations, mass ratio, and pounding stiffness of MPTMDs were studied. The simulations showed that the number of MPTMDs and mass ratio are both significant in suppressing the wind/traffic/bridge coupled vibration; however, the pounding stiffness is not sensitive in suppressing the bridge vibration.
\end{abstract}

Keywords: wind/traffic/bridge coupled system; vibration suppression; energy dissipation; pounding tuned mass damper (PTMD); multiple pounding tuned mass dampers (MPTMDs)

\section{Introduction}

The bridge vibrations under wind and stochastic traffic loads have been extensively studied, and great successes have been achieved during the recent decades. The dynamic performance of bridges is affected by many factors, such as the wind speed, vehicle type, and road surface condition [1-5]. The results of all above research have shown that the dynamic responses of bridges induced by wind and stochastic traffic loads usually exceed that anticipated on highway bridges.

To control the dynamic response of the primary structure, a method of suppressing the vibration of structures is to use an energy dissipative system. One such system is the tuned mass damper (TMD) system, which is used as a secondary vibration system and is connected to the primary structure at suitable positions. Since the TMD concept was first investigated by Frahm [6], much research has been carried out to examine its effectiveness for various dynamic load applications. Much of the previous research efforts were focused on optimizing the TMD parameters and suppressing the bridge vibration under wind or seismic loads [7-15]. However, we found few studies on applying TMDs to suppress bridge vibrations induced by combined wind and traffic loads [16,17]. Recently, a new damping system, pounding tuned mass dampers (PTMD), was proposed and obtained from the references [18-20]. In the PTMD design, the damper has a moving mass block (which is similar to that of a traditional TMD) and an additional delimiter covered with viscoelastic material to restrict 
the stroke of the mass block and dissipate energy via impacts or pounding [19-21]. Compared with a traditional TMD system, the PTMD can simultaneously suppress vibrations in two directions with easy installation and maintenance [18,19]. In addition, the PTMD has larger energy dissipating capacity through impact and is more robust to the system uncertainty compared with a regular TMD [20-22]. However, to the best of the authors' knowledge, very few studies were found on applying PTMDs to suppress the vehicle-induced bridge vibrations.

In this study, a multiple PTMD (MPTMD) system was designed for suppression of wind and traffic induced vibration of a highway bridge. A comprehensive numerical simulation of the traffic/bridge/MPTMD coupled system was performed. The wind/traffic/bridge/MPTMD coupled equations were established by combining the equations of motion of both the bridge and vehicles in traffic, where the displacement and interaction force relationship between the tire and bridge surface roughness was used. For the purpose of comparing the suppressing effectiveness, the parameter study of the different numbers and locations, mass ratio, and pounding stiffness of MPTMD were studied.

\section{Methodology of the Traffic-Bridge Coupled System with MPTMD}

\subsection{Equivalent Vehicle Model Approach in Traffic}

As discussed by Liu et al. [23], the traffic-bridge coupled system can consider various types and numbers of vehicles at any location on the bridge. In order to simplify the vehicular models in traffic, all the vehicles are classified as three types: (1) heavy multi-axle trucks; (2) light trucks and buses; and (3) sedan cars. Only heavy trucks are modeled with 18-DOF(Degree of Freedom) full scale vehicle model, and the other light trucks and sedan cars are used with the 3-DOF vehicle model to be computationally efficient. The 18-DOF and 3-DOF vehicle models are shown in Figures 1 and 2, respectively. The detailed vehicle parameters can be obtained from Yin et al. [24,25].

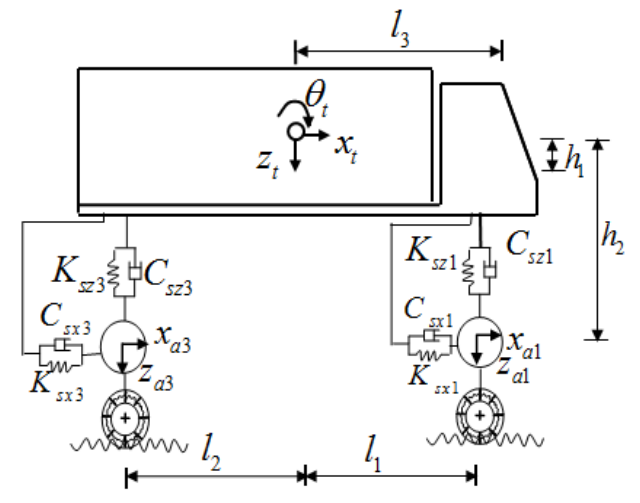

(a)

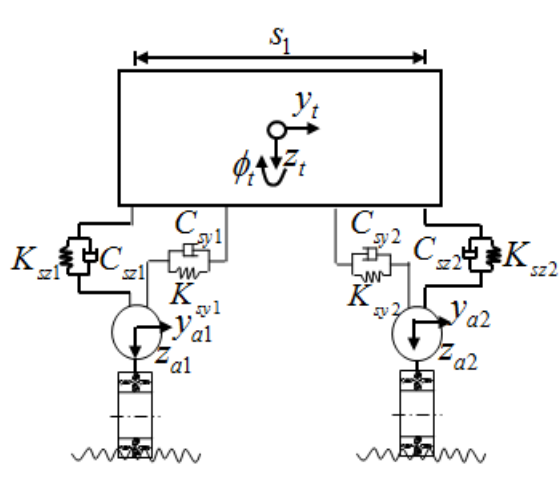

(b)

Figure 1. An 18-DOF full-scale vehicle model. (a) Elevation view. (b) Cross-section view.

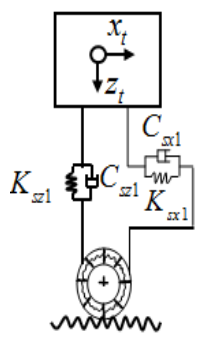

(a)

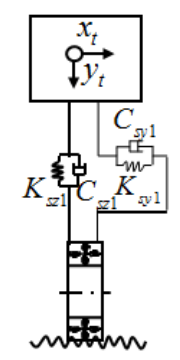

(b)

Figure 2. A 3-DOFs vehicle model with three-dimensional (3-D) vibrations. (a) Elevation view. (b) Cross-section view. 


\subsection{Equation of Motion of the Vehicle}

The equation of motion for a vehicle can be expressed as follows:

$$
\left[\mathrm{M}_{\mathrm{v}}\right]\left\{\ddot{\mathrm{Y}}_{\mathrm{v}}\right\}+\left[\mathrm{C}_{\mathrm{v}}\right]\left\{\dot{\mathrm{Y}}_{\mathrm{v}}\right\}+\left[\mathrm{K}_{\mathrm{v}}\right]\left\{\mathrm{Y}_{\mathrm{v}}\right\}=\left\{\mathrm{F}_{\mathrm{G}}\right\}+\left\{\mathrm{F}_{\mathrm{v}-\mathrm{p}}\right\}+\left\{\mathrm{F}_{\mathrm{vw}}\right\}
$$

where $\left[\mathrm{M}_{\mathrm{V}}\right],\left[\mathrm{C}_{\mathrm{V}}\right]$, and $\left[\mathrm{K}_{\mathrm{v}}\right]$ are the mass, damping, and stiffness matrices of the vehicle, respectively; $\left\{\mathrm{Y}_{\mathrm{v}}\right\}$ is the vector including the displacements of the vehicle; $\left\{\ddot{\mathrm{Y}}_{\mathrm{v}}\right\},\left\{\dot{\mathrm{Y}}_{\mathrm{v}}\right\}$ are respectively the vector including the acceleration and velocity of the vehicle; $\left\{\mathrm{F}_{\mathrm{G}}\right\}$ is the gravity force vector of the vehicle; $\left\{\mathrm{F}_{\mathrm{v}-\mathrm{p}}\right\}$ is the vector of the wheel-pavement contact forces acting on the vehicle; and $\left\{\mathrm{F}_{\mathrm{vw}}\right\}$ is the vector of the wind forces acting on the vehicle [5].

\subsection{Equation of Motion of the Bridge}

The structural nonlinearity is typically considered in the static analysis before a dynamic analysis is conducted. Equations of motions in the three directions including vertical, lateral, and torsion of the bridge with the mode superposition technique can be obtained in a matrix form as [2]:

$$
\left[\mathrm{M}_{\mathrm{b}}\right]\left\{\ddot{\mathrm{Y}}_{\mathrm{b}}\right\}+\left[\mathrm{C}_{\mathrm{b}}\right]\left\{\dot{\mathrm{Y}}_{\mathrm{b}}\right\}+\left[\mathrm{K}_{\mathrm{b}}\right]\left\{\mathrm{Y}_{\mathrm{b}}\right\}=\left\{\mathrm{F}_{\mathrm{b}-\mathrm{v}}+\mathrm{F}_{\mathrm{b}-\mathrm{p}}+\mathrm{F}_{\mathrm{bw}}\right\}
$$

where $\left[M_{b}\right],\left[C_{b}\right]$, and $\left[K_{b}\right]$ are the mass, damping, and stiffness matrices of the bridge, respectively; $\left\{\mathrm{Y}_{\mathrm{b}}\right\}$ is the displacement vector for all DOFs of the bridge; $\left\{\dot{\mathrm{Y}}_{\mathrm{b}}\right\}$ and $\left\{\ddot{Y}_{\mathrm{b}}\right\}$ are the first and second derivative of $\left\{\mathrm{Y}_{\mathrm{b}}\right\}$ with respect to time, respectively; $\left\{\mathrm{F}_{\mathrm{b}-\mathrm{v}}\right\}$ is a vector containing all external forces acting on the bridge; $\left\{\mathrm{F}_{\mathrm{b}-\mathrm{p}}\right\}$ is the interacting force between the PTMD and the bridge, and $\left\{\mathrm{F}_{\mathrm{bw}}\right\}$ is the vector of the wind forces acting on the bridge.

\subsection{Basics about PTMD and Introduction to MPTMD}

In the previous study of Song et al. [20], the comparison of the schematic of a TMD system, an impact damper, and the PTMD system was given. In the PTMD design in this paper, the damper has a moving mass block, which is similar to that of a regular TMD, and a delimiter is covered with viscoelastic material to restrict the stroke of the mass block and dissipate energy via impacts or pounding $[19,20]$. Figures 3 and 4 illustrate MPTMD designed for this purpose. It can be seen that the PTMD consists of two parts-the TMD and the delimiter covered with viscoelastic material. For the multiple PTMD design, the MPTMD with $n$ number of parallelly-placed PTMDs can be installed on a bridge structure at section $x=x_{s}$, as shown in Figure 4. To obtain the effectiveness of suppressing vibration and the parameters of the pounding force, the small-scale PTMD equipment was designed and used to control vibration a pipeline structure. More details on the experimental setup can be obtained from the Song et al. [20] and Zhang et al. [18]. 

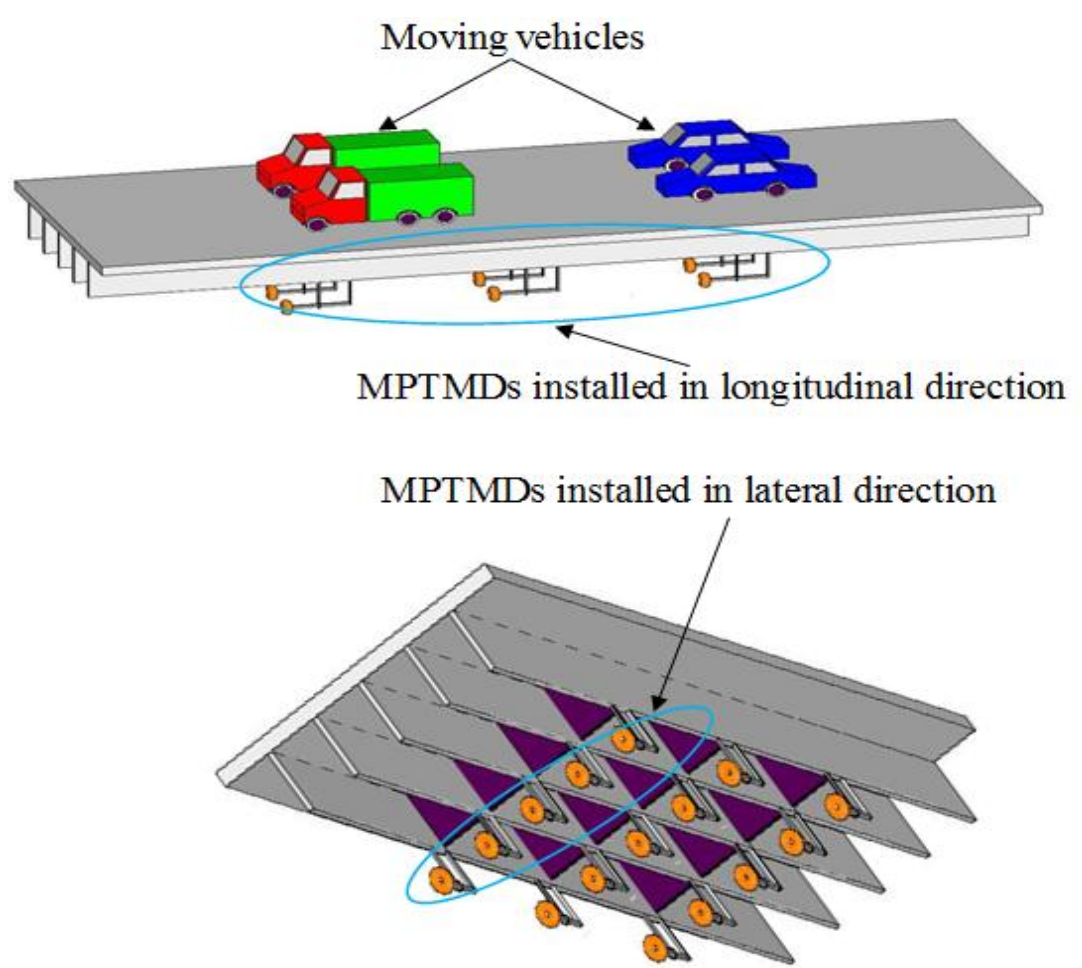

Figure 3. Traffic-bridge coupled system with multiple pounding tuned mass dampers (MPTMDs).

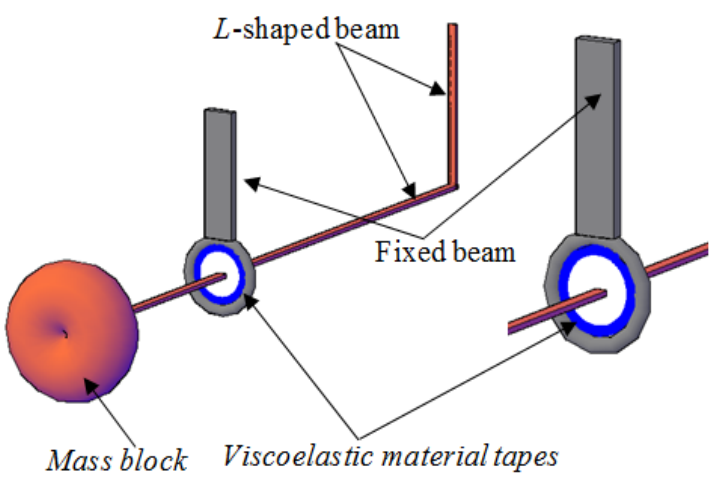

Figure 4. Components of a pounding tuned mass damper (PTMD) system.

\subsection{Equations of Motion of the MPTMD}

The equations of motion that represent the interaction between each PTMD and the bridge are:

$$
\begin{gathered}
m_{p} \ddot{y}_{p v}(t)+c_{p v} \dot{y}_{p v}(t)+k_{p v} y_{p v}(t)=-f_{p-b}^{v}(t)-H f_{p-b}^{v p}(t) \\
m_{p} \ddot{y}_{p l}(t)+c_{p l} \dot{y}_{p l}(t)+k_{p l} y_{p l}(t)=-f_{p-b} l(t)-H f_{p-b} l p(t) \\
{\left[\mathrm{M}_{\mathrm{p}}\right]\left\{\ddot{\mathrm{U}}_{\mathrm{p}}\right\}+\left[\mathrm{C}_{\mathrm{p}}\right]\left\{\dot{\mathrm{U}}_{\mathrm{p}}\right\}+\left[\mathrm{K}_{\mathrm{p}}\right]\left\{\mathrm{U}_{\mathrm{p}}\right\}=\left\{\mathrm{F}_{\mathrm{p}-\mathrm{b}}\right\}+\mathrm{H} \Gamma\left\{\mathrm{F}_{\mathrm{p}-\mathrm{b}} \mathrm{p}\right\}}
\end{gathered}
$$

where $m_{p}$ is the mass of the PTMD; $c_{p v}$ and $c_{p l}$ are the damping of the PTMD in the vertical and lateral direction; $k_{p v}$ and $k_{p l}$ are the stiffness of the PTMD; $f_{p-b} l(t)$ is the force produced by the relative motion between the bridge and the PTMD in the lateral direction; $f_{p-b}{ }^{v}(t)$ denotes that force in the vertical direction. $f_{p-b} v p(t)$ and $f_{p-b}^{l p}(t)$ are the pounding forces in the vertical direction and horizontal direction, which can be calculated using Equations (3)-(5), and $\left[\mathrm{M}_{\mathrm{p}}\right],\left[\mathrm{C}_{\mathrm{p}}\right]$, and $\left[\mathrm{K}_{\mathrm{p}}\right]$ are the mass, damping, and stiffness matrices of the PTMD, respectively; $\left\{\mathrm{U}_{\mathrm{p}}\right\},\left\{\ddot{\mathrm{U}}_{\mathrm{p}}\right\},\left\{\dot{\mathrm{U}}_{\mathrm{p}}\right\}$ are the displacement, 
acceleration, and velocity vector for all DOFs of the PTMD, and the variable $H$ describes the direction of the pounding force; $\Gamma$ denotes the location of the pounding forces.

\subsection{Model of the Pounding Force}

A numerical model is required to accurately analyze the dynamic response of the bridge structure controlled by a PTMD. Several models were proposed to study the effect of the PTMD on the major structure in dynamic analysis during the past decade. Among them, the nonlinear model based on the Hertz contact element in conjunction with a damper is the most appropriate [22] and is thus adopted in this paper.

The force produced by the relative motion between the bridge and the PTMD is expressed as:

$$
f_{p-b}^{v}(t)=k_{p v}\left[y_{b}^{v}-y_{p}^{v}\right] ; f_{p-b}^{l}(t)=k_{p l}\left[y_{b}^{l}-y_{p}^{l}\right]
$$

The pounding force is expressed as:

$$
f_{p-b}^{v p}(t)=\left\{\begin{array}{cl}
\beta\left(x_{1}-x_{2}-g_{p}\right)^{\frac{3}{2}}+c\left(\dot{x}_{1}-\dot{x}_{2}\right), & x_{1}-x_{2}-g_{p}>0, \dot{x}_{1}-\dot{x}_{2}>0 \\
\beta\left(x_{1}-x_{2}-g_{p}\right)^{\frac{3}{2}}, & x_{1}-x_{2}-g_{p}>0, \dot{x}_{1}-\dot{x}_{2}<0 \\
0, & x_{1}-x_{2}-g_{p}<0
\end{array}\right.
$$

where $x_{1}$ and $x_{2}$ are the displacements of the pounding motion limiting collar and the mass block, and $g_{p}$ is the gap between them. $x_{1}-x_{2}-g_{p}$ denotes the relative pounding deformation, and $\dot{x}_{1}-\dot{x}_{2}$ is the relative velocity. $\beta$ is the pounding stiffness coefficient that mainly depends on material properties and the geometry of colliding bodies. Since the viscoelastic material is highly nonlinear, the impact damping $c$ is not a constant. $c$ depends on the pounding stiffness and the deformation of the viscoelastic layer. At any instant of time, $c$ can be obtained from Equation (8) [26]:

$$
\begin{gathered}
c=2 \xi \sqrt{\beta \sqrt{x_{1}-x_{2}-g_{p}} \frac{m_{1} m_{2}}{m_{1}+m_{2}}} \\
\xi=\frac{9 \sqrt{5}}{2} \frac{1-e^{2}}{e(e(9 \pi-16)+16)}
\end{gathered}
$$

where $m_{1}$ and $m_{2}$ are the mass of the two colliding bodies, and $\xi$ is the impact damping ratio correlated with the coefficient of restitution $e$, which is defined as the relation between the post impact (final) relative velocity. When $e=0$ stands for a perfectly plastic impact, $e=1$ stands for a fully elastic impact.

After assessing the value of $\xi$, the pounding stiffness $\beta$ can be determined numerically through interactive simulation, which fits the experimentally obtained pounding force time histories.

\subsection{Assembly of the Traffic-Bridge Coupled System with MPTMD}

Using the displacement relationship and the interaction force relationship at the contact points between the bridge and vehicles in traffic, the traffic-bridge coupled system with MPTMD can be established by combining the equations of motion of both the bridge and vehicles, as shown below:

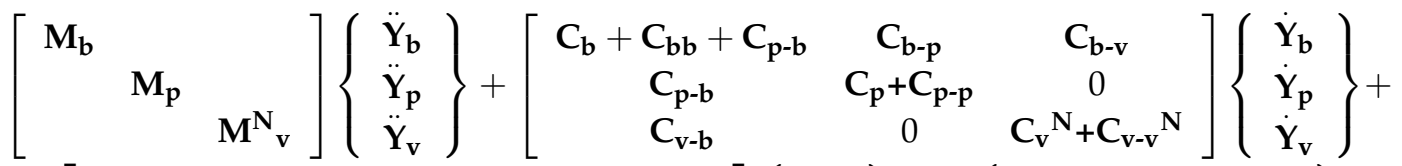

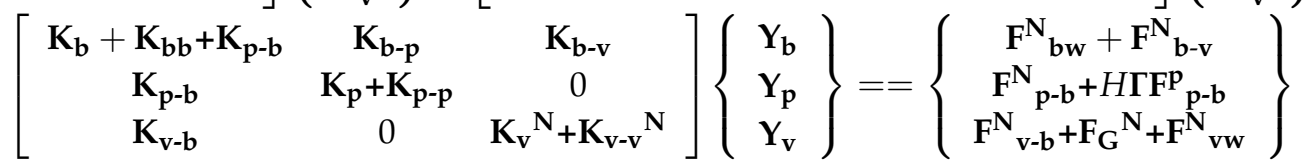


where $\mathrm{N}$ is the number of vehicles traveling on the bridge; $\mathbf{M}_{\mathbf{v}} \mathbf{N}, \mathbf{C}_{\mathbf{v}} \mathbf{N}$, and $\mathbf{K}_{\mathbf{v}} \mathbf{N}$ are mass, damping, and stiffness matrices for the vehicle, respectively; $\mathbf{C}^{\mathbf{N}}{ }_{\mathbf{b} \text {-vb }}$ and $\mathbf{K}^{\mathbf{N}}{ }_{\mathbf{b} \text {-vb }}$ are damping and stiffness contribution to the bridge structure due to the coupling effects between the $\mathrm{N}$ vehicles in the vehicle and the bridge system, respectively; $\mathbf{C}^{\mathbf{N}}{ }_{\mathbf{b} \text {-v }}$ and $\mathbf{K}^{\mathbf{N}}{ }_{\mathbf{b} \text {-v }}$ are the coupled stiffness and damping matrices contributing to bridge vibration from the $\mathrm{N}$ vehicles in traffic, respectively; $\mathbf{C}_{\mathbf{v}-\mathbf{b}}^{\mathbf{N}}$ and $\mathbf{K}^{\mathbf{N}}{ }_{\mathbf{v}-\mathbf{b}}$ are the coupled damping and stiffness matrices contributing to the vibration of the $\mathrm{N}$ vehicles, respectively; $\mathbf{C}_{\mathbf{v}-\mathbf{v}} \mathbf{N}$ and $\mathbf{K}_{\mathbf{v}-\mathbf{v}}{ }^{\mathbf{N}}$ are the coupled damping and stiffness matrices of induced by other vehicles, respectively. Equation (10) can be solved by the improved New-mark method in the time domain.

\subsection{Method of Evaluating Ride Comfort}

To evaluate the ride comfort, the ISO2631-1 [27] specifies the root-mean-square (RMS) magnitudes of the vibration acceleration as the standard for ride comfort, as shown in Table 1.

Table 1. Ride comfort standard specified in ISO2631-1.

\begin{tabular}{cc}
\hline Vibration Acceleration Magnitudes $\boldsymbol{a}_{\boldsymbol{w}}$ & Comfort or Discomfort \\
\hline Less than $0.315 \mathrm{~m} / \mathrm{s}^{2}$ & Not uncomfortable \\
$0.315 \mathrm{~m} / \mathrm{s}^{2}$ to $0.63 \mathrm{~m} / \mathrm{s}^{2}$ & A little uncomfortable \\
$0.5 \mathrm{~m} / \mathrm{s}^{2}$ to $1 \mathrm{~m} / \mathrm{s}^{2}$ & Fairly uncomfortable \\
$0.8 \mathrm{~m} / \mathrm{s}^{2}$ to $1.6 \mathrm{~m} / \mathrm{s}^{2}$ & Uncomfortable \\
$1.25 \mathrm{~m} / \mathrm{s}^{2}$ to $2.5 \mathrm{~m} / \mathrm{s}^{2}$ & Very uncomfortable \\
Greater than $2 \mathrm{~m} / \mathrm{s}^{2}$ & Extremely uncomfortable \\
\hline
\end{tabular}

For vibrations in more than one direction, the weighted RMS acceleration $a_{w}$ determined from the vibrations in the orthogonal coordinates is calculated as:

$$
a_{w}=\left(k_{a x}^{2} a_{w x}^{2}+k_{a y}^{2} a_{w y}^{2}+k_{a z}^{2} a_{w z}^{2}\right)^{\frac{1}{2}}
$$

where $a_{w x}, a_{w y}$, and $a_{w z}$ are the weighted RMS accelerations with respect to the orthogonal axes $x$, $y$, and $z$, respectively; $k_{a x}, k_{a y}$ and $k_{a z}$ are multiplying factors with the orthogonal axes $x, y$, and $z$, respectively, and:

$$
\left.a_{w j}\right|_{j=x, y, z}=\left[\left.\frac{1}{T} \int_{t=0}^{t=T} a_{w j}^{2}(t)\right|_{j=x, y, z} d t\right]^{\frac{1}{2}}
$$

where $a_{w j}(t) \mid$ is the acceleration as a function of time $\left(\mathrm{m} / \mathrm{s}^{2}\right)$ in the $x, y$, and $z$ axes directions; and $T$ is the duration of the measurement (s).

\section{Numerical Studies}

\subsection{Description of an Existing Bridge}

A typical high-pier bridge is shown in Figure 5. The bridge is a five-span, two-lane straight continuous beam bridge with $812 \mathrm{~m}$ in length and $12.5 \mathrm{~m}$ in width. The highest pier measures $178 \mathrm{~m}$ in height. Figure 6 shows the overview of the bridge and the cross-section of the bridge. The Finite Element (FE) model of the high-pier Bridge is shown in Figure 7. 


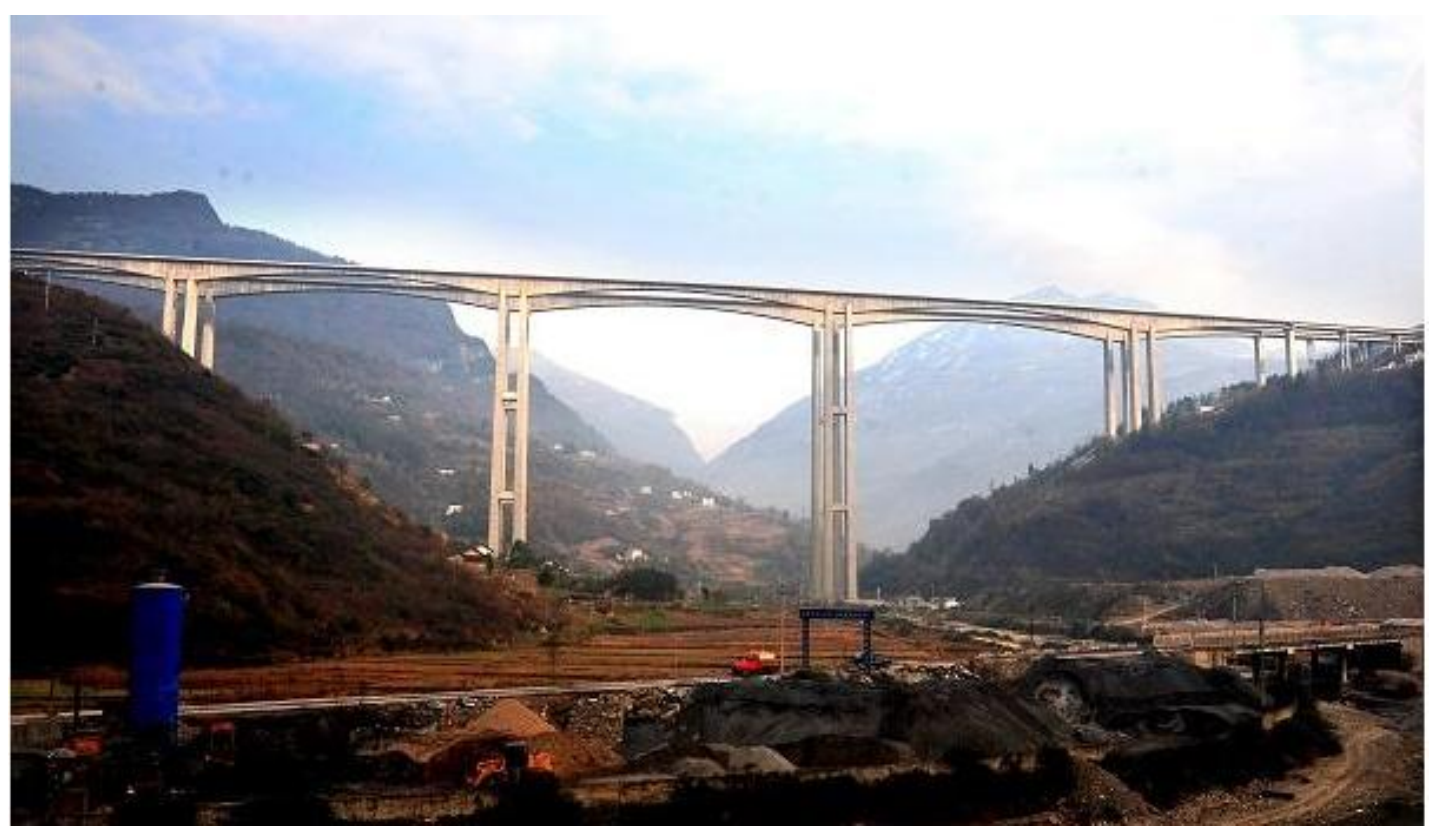

Figure 5. A typical high-pier bridge.

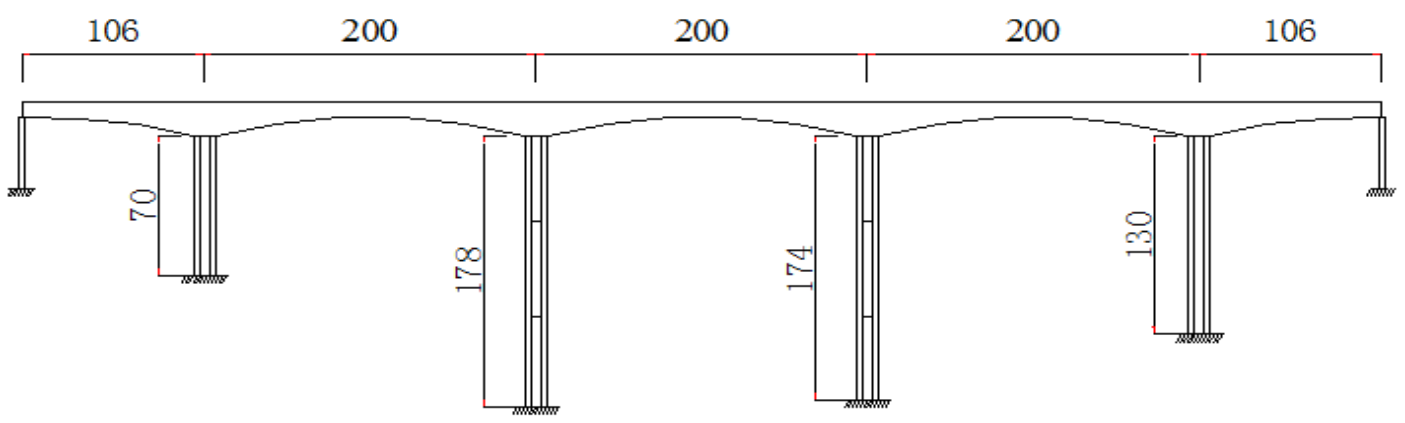

(a)
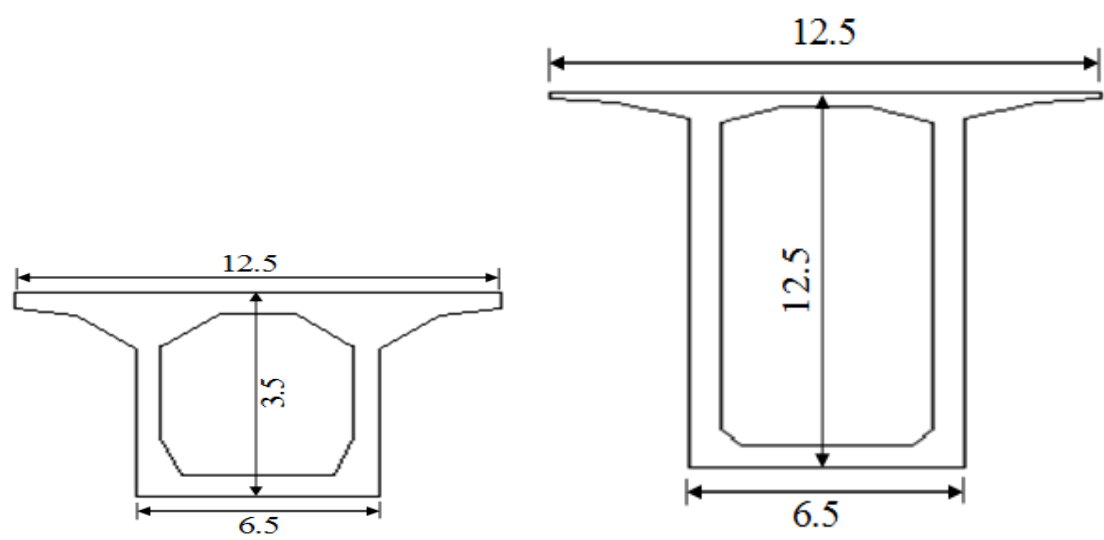

(b)

Figure 6. Elevation of the bridge and the cross-section of the beam. (a) Elevation of the high-pier bridge (m). (b) Cross-section of the beam (m). 


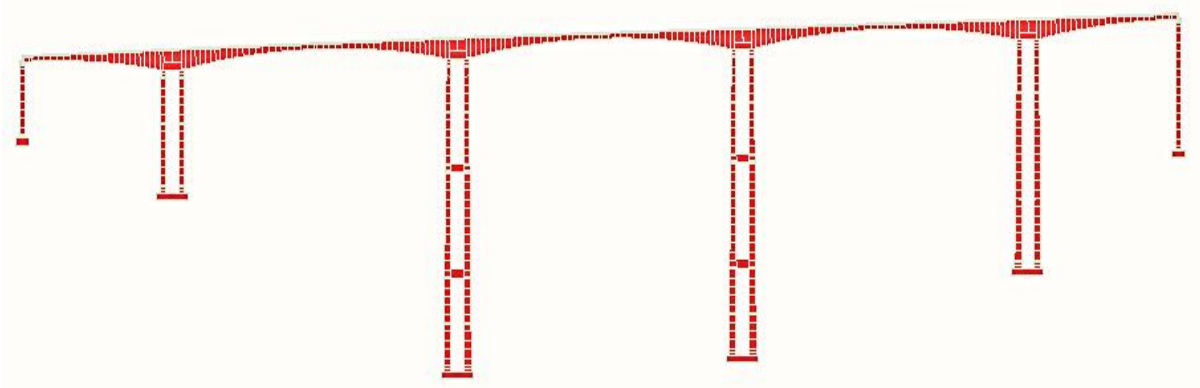

Figure 7. FE model of the Longtan Bridge.

\subsection{The Parameters of Vehicles in Traffic Flow}

In the present study, to simplify the vehicular model, only heavy trucks are modeled with three-dimensional (3-D) vehicle models, while light trucks and sedan cars are modeled using quarter vehicle models to save computational efforts. The 3-D vehicle model and the quarter vehicle model are shown in Figures 1 and 2, respectively, and the parameters of the vehicle models are summarized in Tables 2 and 3. The mechanical and geometric properties of the test truck can be obtained from Yin et al. [24] and are listed in Table 2. The parameters of the quarter vehicle model can be obtained from reference [2] and are also shown in Table 3.

Table 2. Parameters of the 3-D vehicle.

\begin{tabular}{|c|c|}
\hline Parameters & Unit \\
\hline Mass of truck body $m_{t}$ & $26,745 \mathrm{~kg}$ \\
\hline Pitching moment of inertia of truck body $I_{z t}$ & 162,650 kg.m² \\
\hline Rolling moment of inertia of truck body $I_{x t}$ & $67,656 \mathrm{~kg} \cdot \mathrm{m}^{2}$ \\
\hline Mass of truck front axle $m_{a 1}$ & $1513 \mathrm{~kg}$ \\
\hline Rolling moment of inertia of front axle $I_{x a 1}$ & $2360 \mathrm{~kg} \cdot \mathrm{m}^{2}$ \\
\hline Mass of truck rear axle $m_{a 2}$ & $2674 \mathrm{~kg}$ \\
\hline Rolling moment of inertia of rear axle $I_{x a 2}$ & $2360 \mathrm{~kg} \cdot \mathrm{m}^{2}$ \\
\hline Suspension spring stiffness of the first axle $K_{s y}{ }^{1}, K_{s y}{ }^{2}$ & $252,604(\mathrm{~N} / \mathrm{m})$ \\
\hline Suspension damper coefficient of the first axle $D_{s y}{ }^{1}, D_{s y}{ }^{2}$ & 2490 (N.s/m) \\
\hline Suspension spring stiffness of the second axle $K_{s y}{ }^{3}, K_{s y}{ }^{4}$ & $1,806,172(\mathrm{~N} / \mathrm{m})$ \\
\hline Suspension damper coefficient of the second axle $D_{s y}{ }^{3}, D_{s y}{ }^{4}$ & 7982 (N.s/m) \\
\hline Radial direction spring stiffness of the tire $k_{t y}$ & $276,770(\mathrm{~N} / \mathrm{m})$ \\
\hline Radial direction spring damper coefficient of the tire $c_{t y}$ & 1990 (N.s/m) \\
\hline Length of the patch contact & $345 \mathrm{~mm}$ \\
\hline Width of the patch contact & $240 \mathrm{~mm}$ \\
\hline Distance between the front and rear axles $l_{1}$ & $4.85 \mathrm{~m}$ \\
\hline Distance between the front and the center of the truck $l_{2}$ & $3.73 \mathrm{~m}$ \\
\hline Distance between the rear axle and the center of the truck $l_{3}$ & $1.12 \mathrm{~m}$ \\
\hline Distance between the right and left axles $s_{1}, s_{2}$ & $2.40 \mathrm{~m}$ \\
\hline
\end{tabular}

For the purpose of traffic simulation, three different vehicle occupancy coefficients $\rho$ are considered using Equations (1)-(3): smooth traffic $(\rho=0.07)$, median traffic $(\rho=0.15)$, and busy traffic flow $(\rho=0.3)$. It is reasonably found from Table 4 that the mean speed of the traffic flow decreases while the standard deviation of the vehicle speeds increases with the increase of the vehicle occupancy. 
Table 3. The parameters of the quarter vehicle model.

\begin{tabular}{cccc}
\hline Parameters & Unit & Sedan Car & Light Truck \\
\hline Sprung mass & $\mathrm{kg}$ & 1611 & 4870 \\
$\begin{array}{c}\text { Stiffness of suspension system } \\
\left(K_{s x} 1, K_{s y}{ }^{1}, K_{s z}{ }^{1}\right)\end{array}$ & $\mathrm{N} / \mathrm{m}$ & 434,920 & 500,000 \\
Damping $\left(C_{s x}, C_{s y}^{1}, C_{s z}\right)$ & N.s $/ \mathrm{m}$ & 5820 & 20,000 \\
\hline
\end{tabular}

Table 4. Statistical property of traffic flow on bridge.

\begin{tabular}{ccc}
\hline Occupancy & Average Speed $(\mathbf{k m} / \mathbf{h})$ & Standard Deviation $\mathbf{( k m} / \mathbf{h})$ \\
\hline 0.07 & 94.31 & 15.58 \\
\hline 0.15 & 85.56 & 24.42 \\
\hline 0.30 & 50.32 & 39.76 \\
\hline
\end{tabular}

\subsection{The Parameters of MPTMDs Installed on the Bridge}

According to the preliminary analyses, it is desirable to tune the MPTMD to the bridge's dominant mode in one direction, and the MPTMD are positioned at the mid-span of the each span (Figure 8) where the dynamic response is the maximum. In the case of MPTMDs, all the PTMD systems can be concentrated at the mid-span or can be distributed along the length of the bridge. Figure 8 shows the simplified model of the bridge with MPTMD attached at equal intervals under the bridge. Figure $9 \mathrm{~b}$ shows the N locations of parallelly-placed single PTMDs installed with equal or unequal intervals on the bridge at sections I-I (II-II; III-III), and Figure 8c shows the N numbers of single PTMD located at cross-section in a lateral direction.

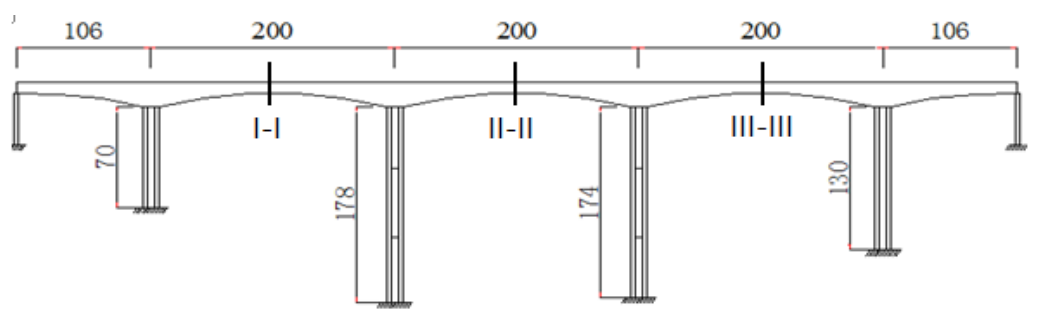

(a)

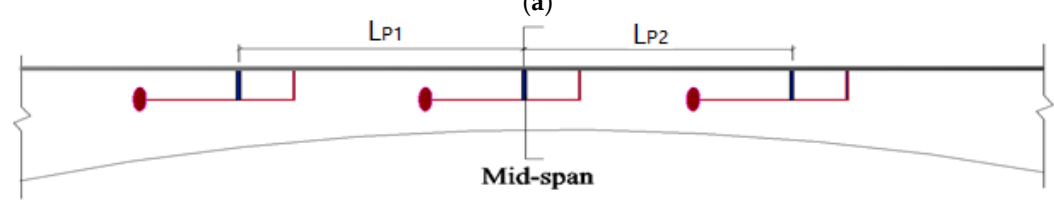

(b)

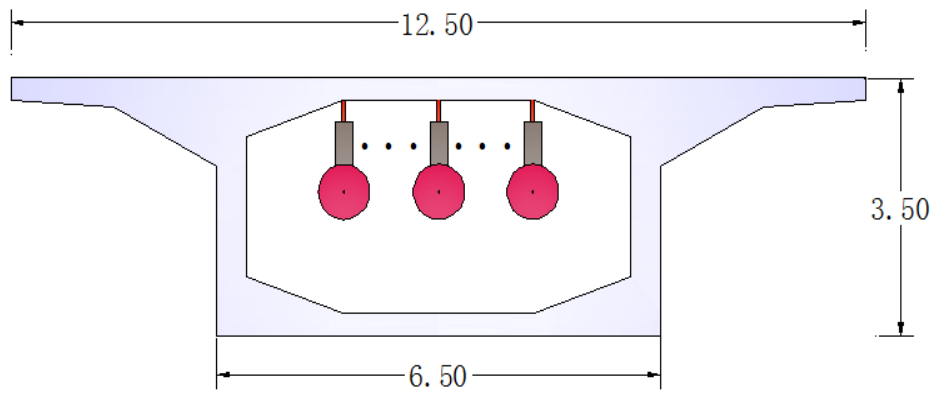

(c)

Figure 8. Locations of the MPTMD at the bridge. (a) Locations of the MPTMD at each span (m). (b) Longitudinal locations of the MPTMD at each mid-span (I-I; II-II; III-III) (m). (c) Lateral locations of the MPTMD at each mid-span (I-I; II-II; III-III) (m). 


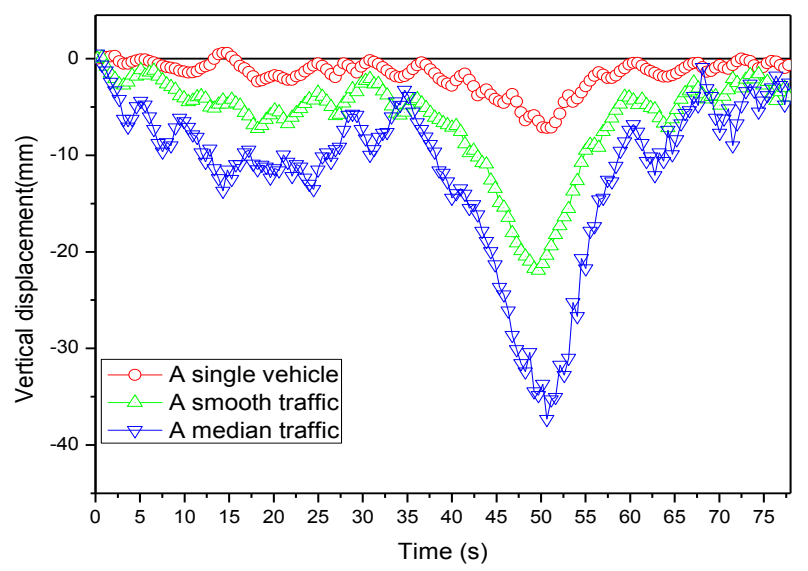

(a)

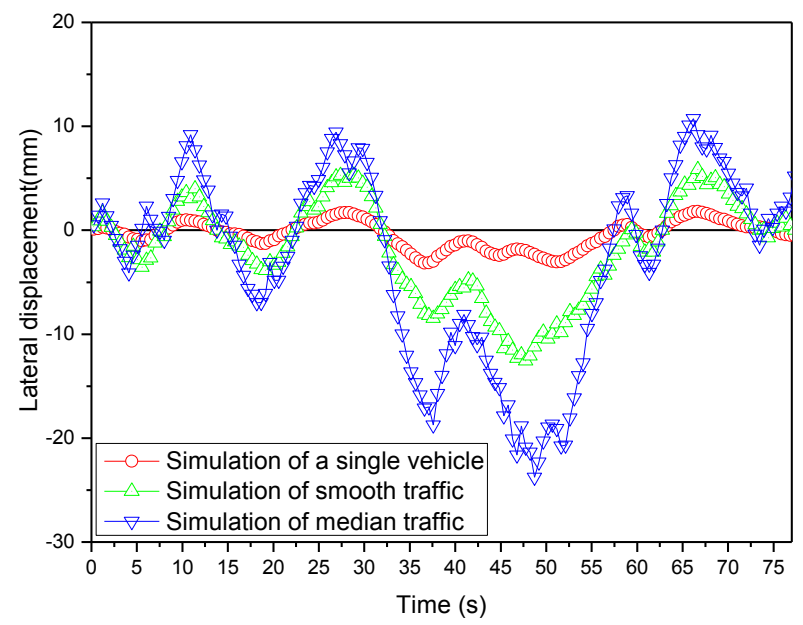

(b)

Figure 9. Comparison of simulated solutions of the mid-span displacement. (a) Vertical displacement. (b) Lateral displacement.

In the studies $[9,16,17]$, the damping ratios of all the bridges are assumed to be 0.02 . The mass ratio of both MPTMDs is selected as $1 \%$ in this study. The coefficient $e$ of restitution of the each PTMD is set as 0.5 , and the pounding stiffness $\beta$ of the PTMD is $25,000 \mathrm{Nm}^{-3 / 2}$. The MPTMD system can own a wider frequency range, and each PTMD contains respective adjustable natural frequency, as shown in Table 5.

Table 5. Multiple tuned mass damper parameters.

\begin{tabular}{ccccc}
\hline $\begin{array}{c}\text { Longitudinal Locations } \\
\text { of PTMDs, } \boldsymbol{n}\end{array}$ & (II-II) & (I-I; II-II; III-III) & (I-I; II-II; III-III) & (I-I; II-II; III-III) \\
\hline Number of PTMDs, $n$ & 1 & $\begin{array}{c}\text { (One PTMD of } \\
\text { each section) }\end{array}$ & $\begin{array}{c}\text { ( } \text { (Two PTMDs of } \\
\text { each section) }\end{array}$ & $\begin{array}{c}\text { (Three PTMDs of } \\
\text { each section) }\end{array}$ \\
\hline Optimal frequency ratio & \multirow{2}{*}{1.0} & $0.95 ; 1.0 ; 1.1$ & $\begin{array}{c}0.90 ; 0.95 ; 1.0 ; \\
1.05 ; 1.1 ; 1.15\end{array}$ & $\begin{array}{c}0.85 ; 0.88 ; 0.90 ; 0.95 ; 1.0 \\
1.05 ; 1.10 ; 1.15 ; 1.20\end{array}$ \\
\hline
\end{tabular}

To compare the performance of the MPTMD with different parameters, the vibration reduction ratio is defined as:

$$
\eta_{C t r l}=\frac{Y_{O}-Y_{C t r l}}{Y_{O}} \times 100 \%
$$

where $Y_{O}$ and $Y_{C t r l}$ are the maximum displacement of the coupled system without and with PTMD. 


\section{Numerical Simulations}

\subsection{Comparison of the Bridge Responses with Different Traffic Flow Occupancies}

As the preliminary analyses of MPTMDs on the wind/traffic/bridge/MPTMD coupled vibration, the bridge responses with different traffic flow occupancies are studied firstly in this section. The time histories of the vertical and lateral responses at the mid-span of the bridge under three situations with a single vehicle and two types of traffic flow occupancies are presented in Figure 9. It was found that both vertical and lateral displacements at the mid-span increased generally as the vehicle occupancy increased. The vehicle occupancies played a significant role in the response of bridge displacements. For example, Figure 9a shows that the maximal vertical displacements of the bridge increased from $21.92 \mathrm{~mm}$ to $35.29 \mathrm{~mm}$ when the vehicle occupancy changed from the smooth traffic to the median traffic.

\subsection{Comparison of the Bridge Responses under Median Traffic Flow with Different Wind Speeds}

The time histories of the responses at the mid-span of the bridge under two typical wind speeds (weak wind speed $U=2.7 \mathrm{~m} / \mathrm{s}$ and moderate wind speed $U=17.6 \mathrm{~m} / \mathrm{s}$ ) with the median traffic flow occupancy $\rho=0.15$ are presented in Figure 10. It was found that the displacements at the mid-span increased generally with the increase of wind speeds, as expected. The wind speed played a significant role in the bridge displacements. For example, when the wind speed increased from $2.7 \mathrm{~m} / \mathrm{s}$ to $17.6 \mathrm{~m} / \mathrm{s}$, the maximal vertical displacements increased from $56.93 \mathrm{~mm}$ to $73.59 \mathrm{~mm}$, and the maximal lateral displacements increased from $41.76 \mathrm{~mm}$ to $51.60 \mathrm{~mm}$.

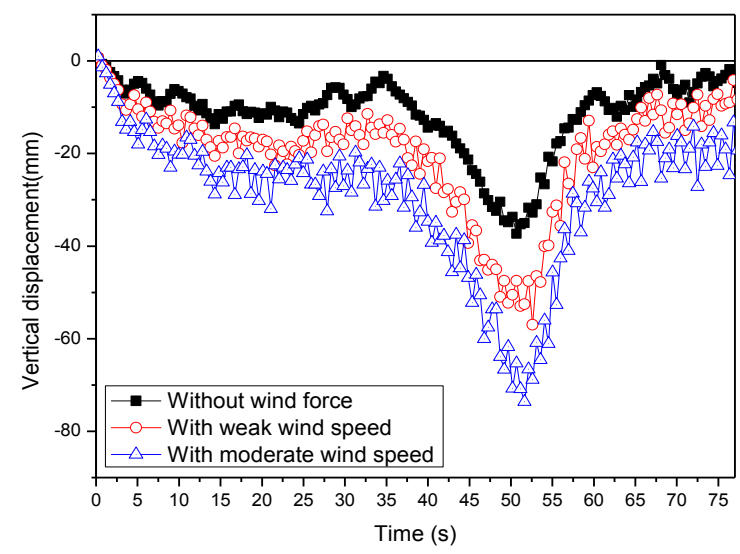

(a)

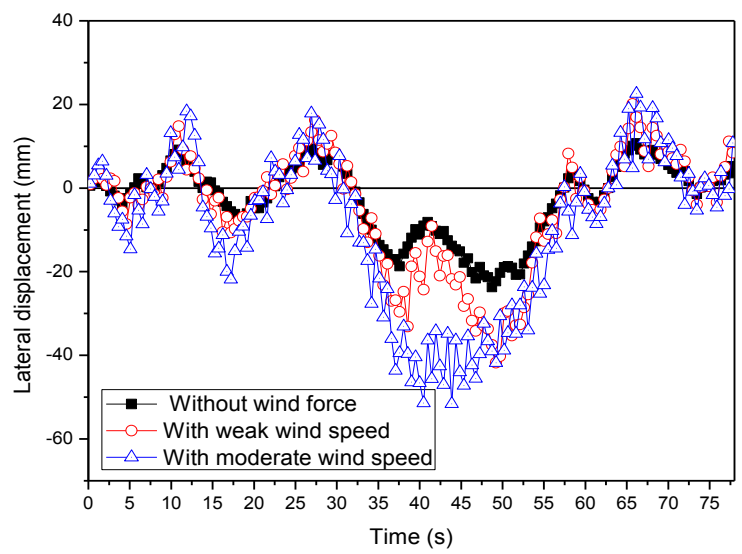

(b)

Figure 10. Comparison of simulated solutions of the mid-span displacement. (a) Vertical displacement (b) Lateral displacement. 


\subsection{Study of MPTMDs on the Wind/Traffic/Bridge/MPTMD Coupled Vibration}

As discussed above, the vertical and lateral displacements induced by traffic are both significant and thus cannot be neglected. Therefore, the vertical and lateral dynamic displacements should be suppressed by MPTMD systems, and the MPTMD systems are tuned respectively to vertical frequency or lateral frequency of the bridge.

(1) Effect of the numbers and locations of MPTMD system

The time histories of the bridge deflections without suppressing the vibration system with and without MPTMD are plotted in Figure 11 and shown in Table 6. It is evident from these figures that the PTMD were very effective in suppressing bridge vibration. The values of responses marked without suppressed systems in the figure were more than those marked by PTMD and MPTMD. Taking an example of vertical displacements of the bridge, the maximal bridge displacement was $73.59 \mathrm{~mm}$ for the situation without a vibration suppression system, while the maximal displacements of the bridge were $63.08 \mathrm{~mm}(14.28 \%)$ and $52.02 \mathrm{~mm}(29.31 \%)$ for situations with single PTMD and three PTMDs, respectively. Therefore, the PTMD and MPTMDs were both effective methods in suppressing the bridge vibration in the wind/traffic/bridge coupled system. Comparing the displacement values with the different numbers of MPTMDs in Table 6, the MPTMD system was more effective in reducing the bridge-forced vibration than it was when only a single PTMD system was installed under the bridge. Using the nine PTMD system, the vibration reduction ratio of the vertical displacements could reach to $36.78 \%$.

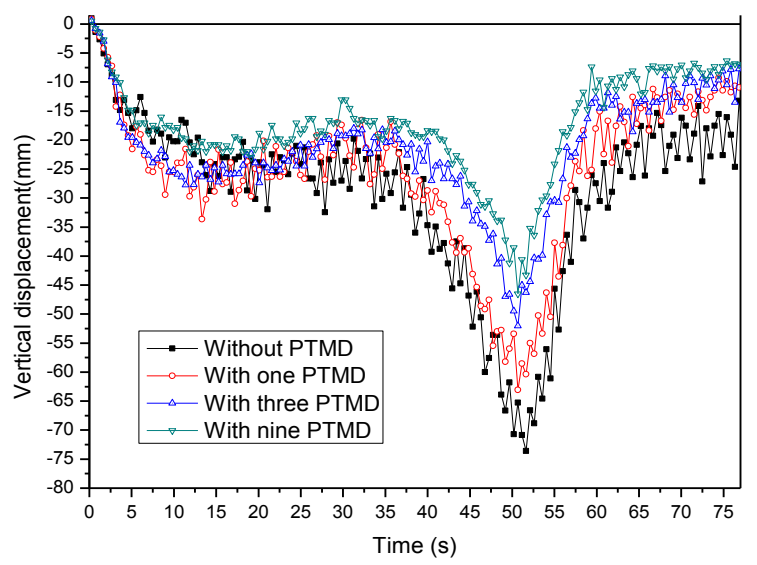

(a)

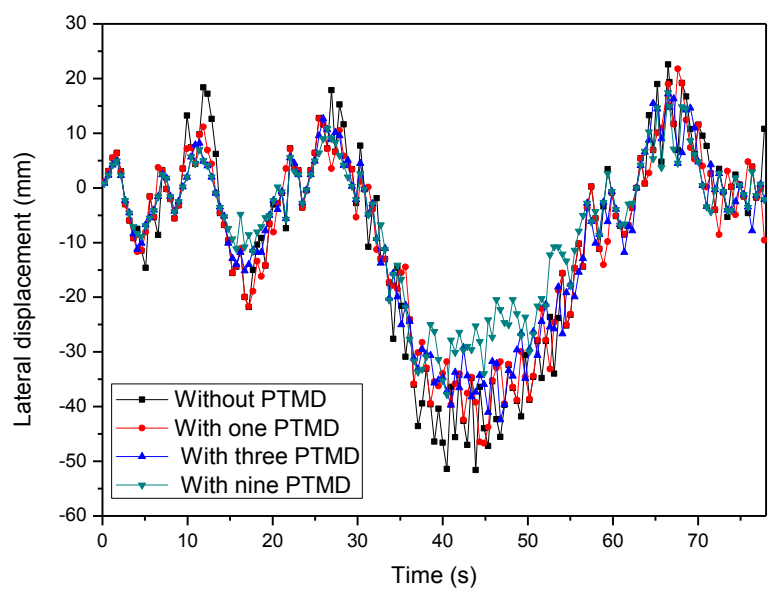

(b)

Figure 11. Comparison of the mid-span displacements with/without MPTMDs. (a) Vertical displacement. (b) Lateral displacement. 
Table 6. Maximum response of bridges with and without PTMD systems.

\begin{tabular}{c|c|c|c|c}
\hline \multirow{2}{*}{ MTMD Condition } & \multicolumn{4}{|c}{ Dynamic Responses } \\
\cline { 2 - 5 } & $\begin{array}{c}\text { Vertical Deflection } \\
(\mathbf{m m})\end{array}$ & Reduction Ratio & $\begin{array}{c}\text { Lateral } \\
\text { Deflection(mm) }\end{array}$ & Reduction Ratio \\
\hline Without PTMD & 73.59 & & 51.60 & \\
\hline Single PTMD & 63.08 & $(14.28 \%)$ & 46.71 & $(9.48 \%)$ \\
\hline MPTMD(3) & 52.02 & $(29.31 \%)$ & 42.43 & $(17.77 \%)$ \\
\hline MPTMD(6) & 49.32 & $(32.98 \%)$ & 39.42 & $(23.60 \%)$ \\
\hline MPTMD(9) & 46.52 & $(36.78 \%)$ & 37.78 & $(26.78 \%)$ \\
\hline
\end{tabular}

The accelerations of vehicle body and ride comfort are given in Figure 12 and Table 7, respectively. It can be seen that the MPTMDs were very effective in suppressing vehicular acceleration. The values of vehicular acceleration marked without suppressed system in the figure were much more than those marked by MPTMDs. In addition, comparing the acceleration values shown in the Table 7 , it can be seen that MPTMD systems were an effective method in the situation of reducing the ride comfort, and the effectiveness of the MPTMD system was much better than a single PTMD system.

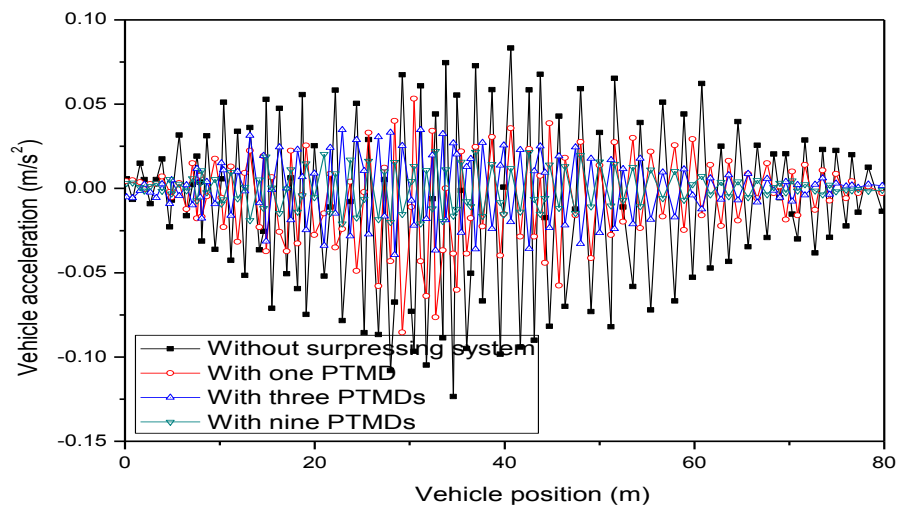

(a)

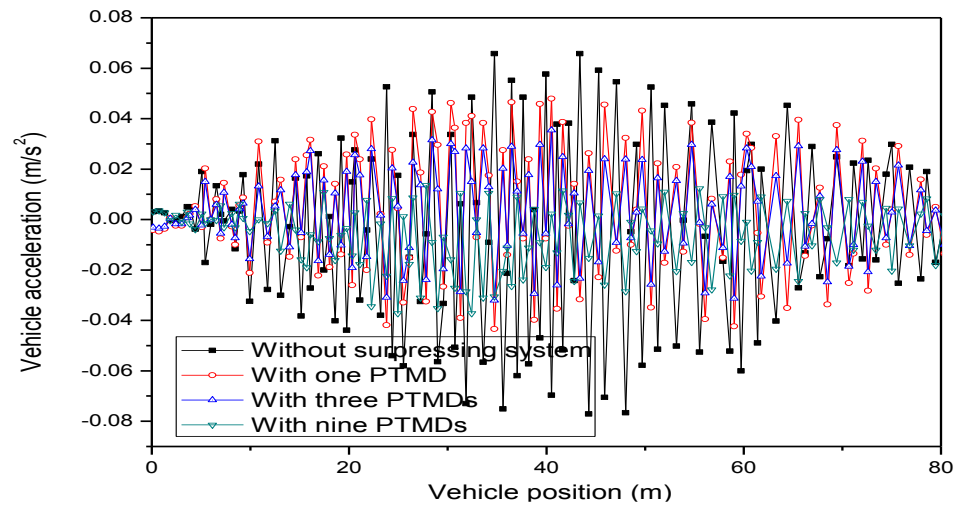

(b)

Figure 12. Comparison of the vehicle accelerations with/without MPTMDs. (a) Vertical accelerations. (b) Lateral accelerations.

Table 7. Ride comfort of vehicles with average roughness.

\begin{tabular}{c|c|c}
\hline \multirow{2}{*}{ MTMD Condition } & \multicolumn{2}{|c}{ Dynamic Responses } \\
\cline { 2 - 3 } & $\boldsymbol{a}_{\mathbf{s u}} \mathbf{( m / \mathbf { s } ^ { \mathbf { 2 } } )}$ & Comfort or Discomfort \\
\hline Without PTMD & 1.04 & Uncomfortable \\
\hline Single PTMD & 0.63 & Fairly uncomfortable \\
\hline MPTMD $(3)$ & 0.43 & A little uncomfortable \\
\hline MPTMD $(6)$ & 0.37 & A little uncomfortable \\
\hline MPTMD $(9)$ & 0.31 & Not uncomfortable \\
\hline
\end{tabular}


(2) Effect of mass ratio of MPTMD system

The mass ratio is one of the key parameters in changing the reduction performance. For economic reasons, the mass ratio is usually from $0.5 \%$ to $2 \%$. As illustrated in Figure 13 and Tables 8 and 9, the vibration reduction ratio of vertical displacements increased significantly, from $21.09 \%$ to $45.47 \%$, with the mass ratio increasing from $0.5 \%$ to $2 \%$, and the ride comfort varied from "uncomfortable" to "not uncomfortable".

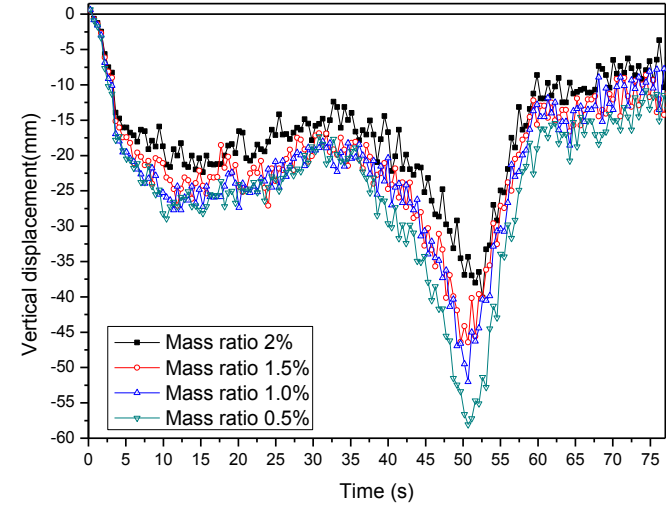

(a)

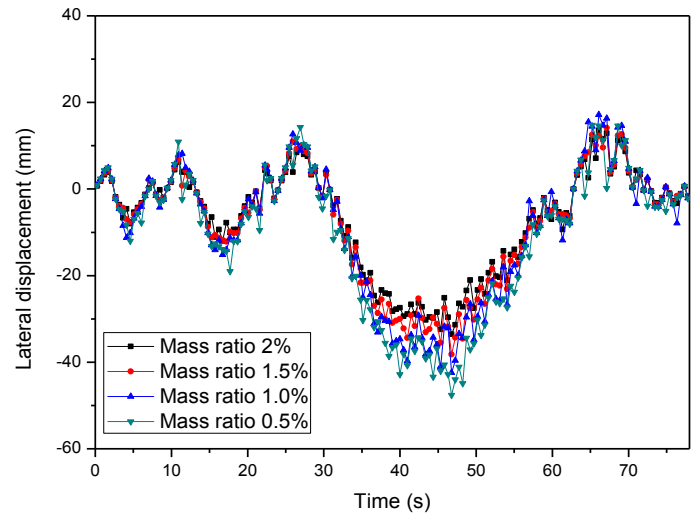

(b)

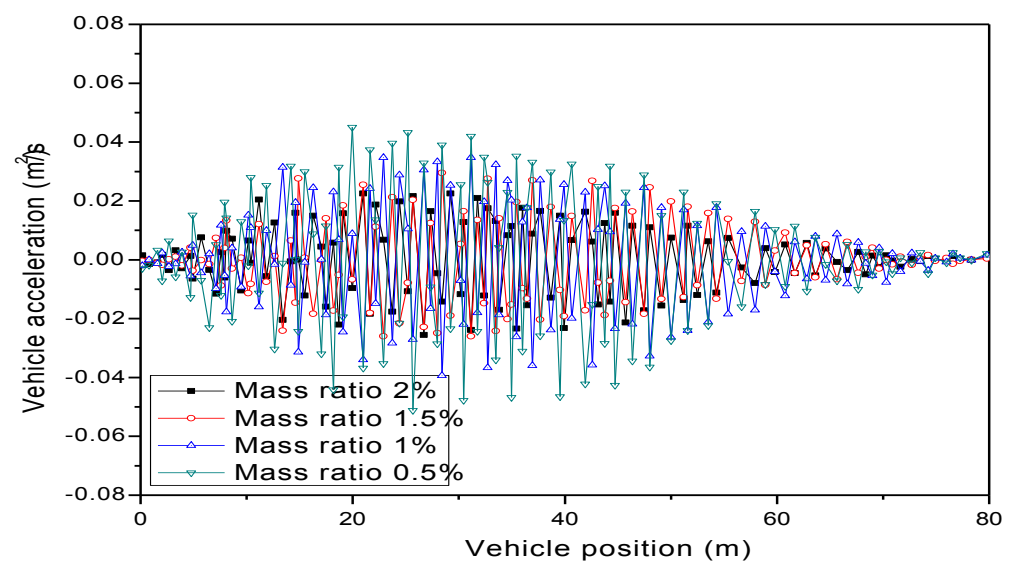

(c)

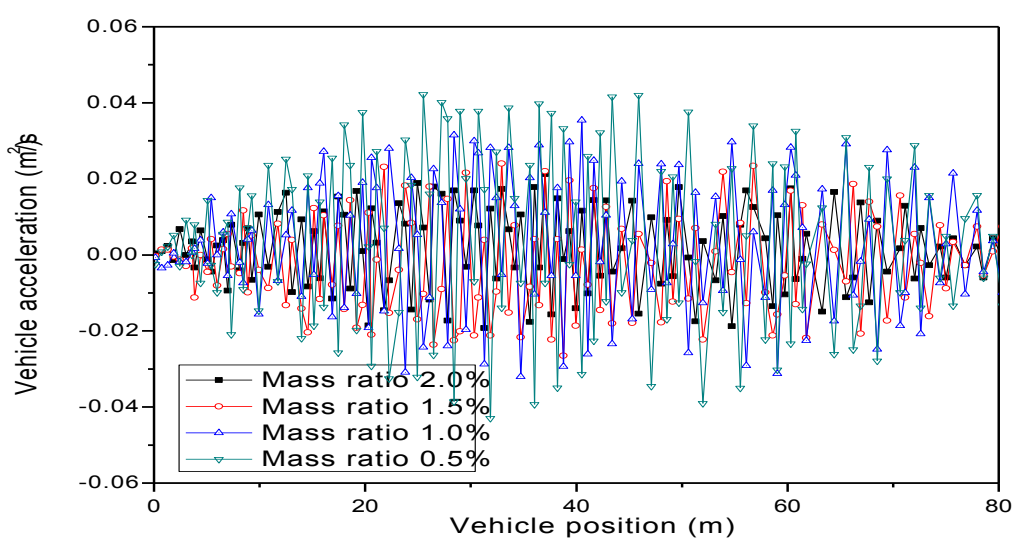

(d)

Figure 13. Parameters study of mass ratio on vehicle-bridge coupled vibration. (a) Vertical displacement. (b) Lateral displacement. (c) Vertical accelerations. (d) Lateral accelerations. 
Table 8. Maximum response of bridges with and without PTMD systems.

\begin{tabular}{c|c|c|c|c}
\hline \multirow{2}{*}{ MTMD Condition } & \multicolumn{4}{|c}{ Dynamic Responses } \\
\cline { 2 - 5 } & $\begin{array}{c}\text { Vertical Deflection } \\
(\mathbf{m m})\end{array}$ & Reduction Ratio & $\begin{array}{c}\text { Lateral } \\
\text { Deflection(mm) }\end{array}$ & \multirow{2}{*}{ Reduction Ratio } \\
\hline Mass ratio 2.0\% & 40.13 & $(45.47 \%)$ & 33.56 & $(37.98 \%)$ \\
\hline Mass ratio 1.5\% & 46.41 & $(36.93 \%)$ & 38.20 & $(25.71 \%)$ \\
\hline Mass ratio 1.0\% & 52.02 & $(29.31 \%)$ & 42.43 & $(21.59 \%)$ \\
\hline Mass ratio 0.5\% & 58.07 & $(21.09 \%)$ & 47.59 & $(12.05 \%)$ \\
\hline
\end{tabular}

Table 9. Ride comfort of vehicles with average roughness.

\begin{tabular}{|c|c|c|}
\hline \multirow{2}{*}{ MTMD Condition } & \multicolumn{2}{|c|}{ Dynamic Responses } \\
\hline & $a_{\mathrm{su}}\left(\mathrm{m} / \mathrm{s}^{2}\right)$ & Comfort or Discomfort \\
\hline Mass ratio $2.0 \%$ & 0.27 & Not uncomfortable \\
\hline Mass ratio $1.5 \%$ & 0.32 & A little uncomfortable \\
\hline Mass ratio $1.0 \%$ & 0.43 & Fairly uncomfortable \\
\hline Mass ratio $0.5 \%$ & 0.56 & Uncomfortable \\
\hline
\end{tabular}

(3) Effect of pounding stiffness of MPTMD system

The pounding stiffness $\beta$ is also a key parameter in modeling the pounding force. It is determined by material properties and geometry of colliding bodies. It varies from 10,000 to 30,000 according to the durability test [18]. In this section, the pounding stiffness was changed to 5000 and 35,000. Other parameters such as the PTMD's mass ratio and number of MPTMDs remained the same. Figures 14 and 15 and Tables 10 and 11 show the effect of pounding stiffness on the bridge displacements and vehicle accelerations. It is seen that the effectiveness of MPTMD control performance was not very sensitive to the change of pounding stiffness. As the pounding stiffness increased from 5000 to 35,000 , the reduction ratio was only decreased from $31.21 \%$ to $27.94 \%$.

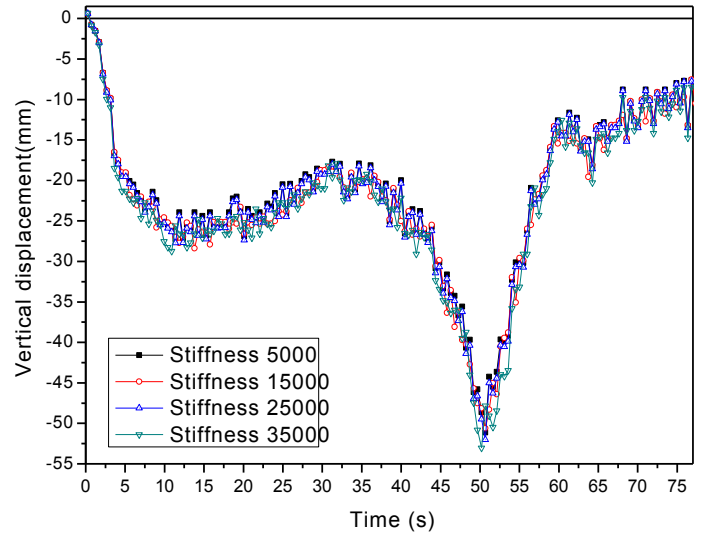

(a)

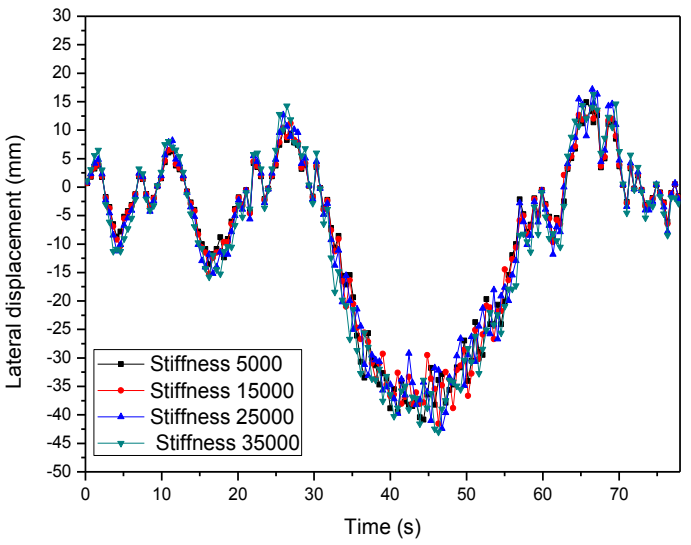

(b)

Figure 14. Parameters study of pounding stiffness on bridge displacements. (a) Vertical displacement. (b) Lateral displacement.

Table 10. Maximum response of bridges with and without PTMD systems.

\begin{tabular}{c|c|c|c|c}
\hline \multirow{2}{*}{$\begin{array}{c}\text { Stiffness } \\
\begin{array}{c}\text { Condition } \\
\left(\mathbf{N m}^{-3 / 2}\right)\end{array}\end{array}$} & $\begin{array}{c}\text { Vertical Deflection } \\
\mathbf{( m m}\end{array}$ & Reduction Ratio & $\begin{array}{c}\text { Lateral Deflection } \\
(\mathbf{m m})\end{array}$ & Reduction Ratio \\
\hline Stiffness 5000 & 50.62 & $(31.21 \%)$ & 40.83 & $(24.54 \%)$ \\
\hline Stiffness 15,000 & 51.12 & $(30.53 \%)$ & 41.56 & $(23.19 \%)$ \\
\hline Stiffness 25,000 & 52.02 & $(29.31 \%)$ & 42.43 & $(21.59 \%)$ \\
\hline Stiffness 35,000 & 53.03 & $(27.94 \%)$ & 42.98 & $(20.57 \%)$ \\
\hline
\end{tabular}




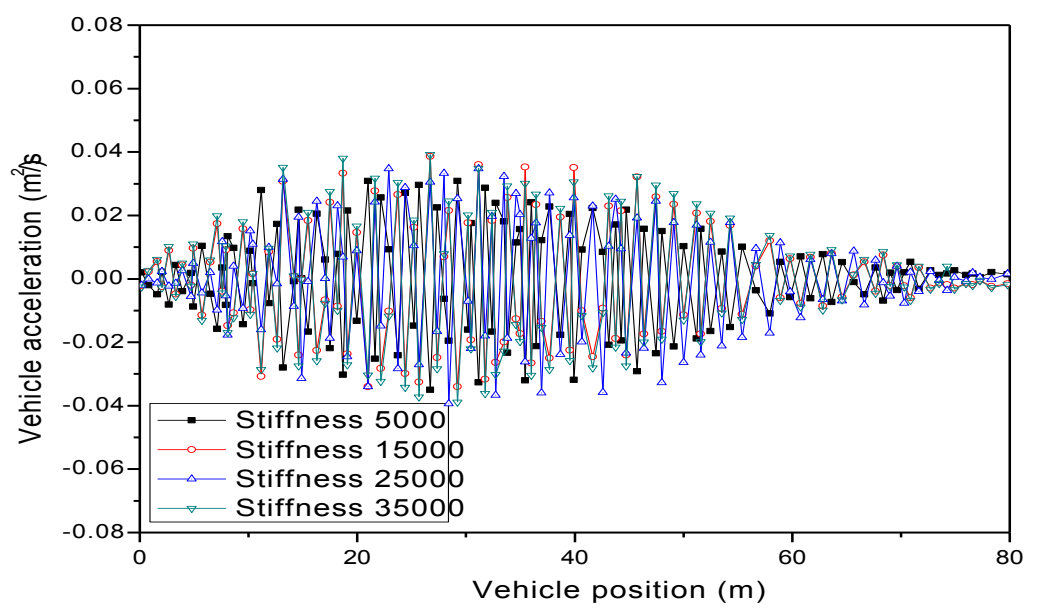

(a)

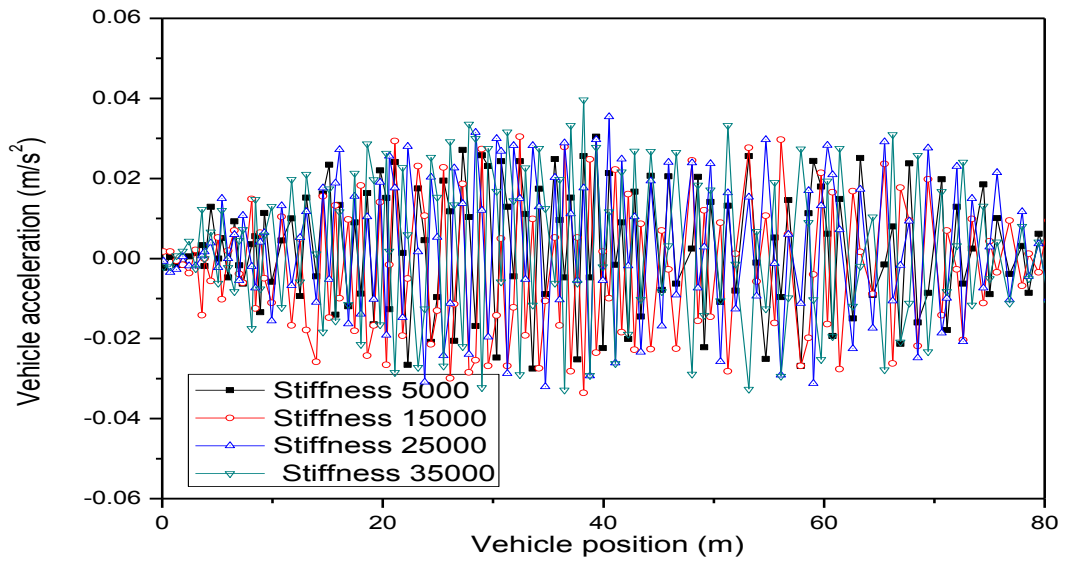

(b)

Figure 15. Parameters study of pounding stiffness on vehicle accelerations. (a) Vertical accelerations. (b) Lateral accelerations.

Table 11. Ride comfort of vehicles with average roughness.

\begin{tabular}{|c|c|c|}
\hline \multirow{2}{*}{$\begin{array}{c}\text { Stiffness Condition } \\
\left(\mathrm{Nm}^{-3 / 2}\right)\end{array}$} & \multicolumn{2}{|c|}{ Dynamic Responses } \\
\hline & $a_{\mathrm{su}}\left(\mathrm{m} / \mathrm{s}^{2}\right)$ & Comfort or Discomfort \\
\hline Stiffness 5000 & 0.38 & A little uncomfortable \\
\hline Stiffness 15,000 & 0.41 & A little uncomfortable \\
\hline Stiffness 25,000 & 0.43 & A little uncomfortable \\
\hline Stiffness 35,000 & 0.46 & A little uncomfortable \\
\hline
\end{tabular}

\section{Conclusions}

In the present study, a new PTMD system was designed with the integration of a tuned mass and a viscoelastic-material covered delimiter for energy dissipation during impacts. A comprehensive numerical simulation of the wind/traffic/bridge/MPTMD coupled system was performed with consideration to the effects of the traffic flow model, the MPTMD systems, and wind forces. The wind/traffic/bridge/MPTMD coupled equations were established by combining the equations of motion of both the bridge and vehicles in traffic, and the displacement and interaction force relationship between the tire and bridge surface roughness was used. For the purpose of comparing the suppressing effectiveness, the parametric study of the different numbers and locations, mass ratio, and pounding stiffness of MPTMD were conducted. The numerical simulations demonstrated that: 
1. The single PTMD and multiple PTMD were both very effective in suppressing vehicular acceleration and bridge displacements induced by the traffic flows in the wind environment. The effectiveness of the multiple PTMD system was much better than that of the single PTMD system.

2. The number of MPTMDs was significant in suppressing the bridge vibration in the wind/traffic/bridge coupled system. Compared with the displacement values under the different numbers of the MPTMD system, the vibration reduction ratio of the vertical displacements could reach $36.78 \%$.

3. The effects of vibration reduction ratio on responses of wind/traffic/bridge coupled system were the mass ratio increasing from $0.5 \%$ to $2 \%$, the bridge displacement increasing significantly from $21.09 \%$ to $45.47 \%$, and the ride comfort varying from "uncomfortable" to "not uncomfortable".

4. The effectiveness of MPTMD control performance was not very sensitive to the change of pounding stiffness. As the pounding stiffness increased from 5000 to 35,000, the reduction ratio was only decreased from $31.21 \%$ to $27.94 \%$.

Author Contributions: The work described in this article is the collaborative development of all authors. X.Y. and G.S. contributed to the idea of data processing and designed the algorithm. Y.L. participated in the writing of the paper.

Acknowledgments: This research was funded by Natural Science Foundation of Hunan Province (Project No.2019JJ40313).

Conflicts of Interest: The authors declare no conflict of interest.

\section{References}

1. Wang, T.L.; Huang, D.Z; Shahawy, M. Dynamic response of multi-girder bridges. J. Struct. Eng. 1992, 118, 2222-2238. [CrossRef]

2. Deng, L.; Cai, C. Identification of Dynamic Vehicular Axle Loads: Demonstration by a Field Study. J. Vib. Control 2010, 17, 183-195. [CrossRef]

3. Yang, Y.-B.; Cheng, M.C.; Chang, K.C. Frequency Variation in Vehicle-Bridge Interaction Systems. Int. J. Str. Stab. Dyn. 2013, 13, 1350019. [CrossRef]

4. Wu, M.X.; Li, Y.L.; Zhang, W. Impacts of wind shielding effects of bridge tower on railway vehicle running performance. Wind Struct. 2017, 25, 63-67.

5. Han, W.; Liu, H.; Wu, J.; Yuan, Y.; Chen, A. Dynamic analysis of long-span cable-stayed bridges under wind and traffic using aerodynamic coefficients considering aerodynamic interference. Wind Struct. 2017, 24, 405-430. [CrossRef]

6. Frahm, H. Device for Damping of Bodies. U.S. Patent 989-958, 18 April 1911.

7. Igusa, T.; $\mathrm{Xu}, \mathrm{K}$. Vibration reduction characteristics of distributed tuned mass dampers. In Proceedings of the Fourth International Conference on Recent Advances in Structural Dynamics, Southampton, UK, 15-18 July 1991; pp. 596-605.

8. Das, A.; Dey, S. Effects of tuned mass dampers on random response of bridges. Comput. Struct. 1992, 43, 745-750. [CrossRef]

9. Jo, B.-W.; Tae, G.-H.; Lee, D.-W. Structural vibration of tuned mass damper-installed three-span steel box bridge. Int. J. Press. Vessels Pip. 2001, 78, 667-675. [CrossRef]

10. Chen, X.; Kareem, A. Efficacy of Tuned Mass Dampers for Bridge Flutter Control. J. Struct. Eng. 2003, 129, 1291-1300. [CrossRef]

11. Marian, L.; Giaralis, A. Optimal design of a novel tuned mass-damper-inerter (TMDI) passive vibration control configuration for stochastically support-excited structural systems. Probab. Eng. Mech. 2014, 38, 156-164. [CrossRef]

12. Tsai, H.C. The effect of tuned-mass dampers on the seismic response of base-isolated structures. Int. J. Solids Struct. 1995, 32, 1195-1210. [CrossRef]

13. Reggio, A.; De Angelis, M. Optimal energy-based seismic design of non-conventional Tuned Mass Damper (TMD) implemented via inter-story isolation. Earthq. Eng. Struct. Dyn. 2015, 44, 1623-1642. [CrossRef] 
14. Alonso-Estebanez, A.; Del Coz Diaz, J.; Alvarez Rabanal, F. Numerical investigation of truck aerodynamics on several classes of infrastructures. Wind Struct. 2018, 26, 35-43.

15. De Domenico, D.; Ricciardi, G. Optimal design and seismic performance of tuned mass damper inerter (TMDI) for structures with nonlinear base isolation systems. Earthq. Eng. Struct. Dyn. 2018, 47, 2539-2560.

16. Li, J.; Su, M.; Fan, L. Vibration Control of Railway Bridges under High-Speed Trains Using Multiple Tuned Mass Dampers. J. Bridge Eng. 2005, 10, 312-320. [CrossRef]

17. Shi, X.; Cai, C. Suppression of Vehicle-induced Bridge Vibration Using Tuned Mass Damper. J. Vib. Control 2008, 14, 1037-1054.

18. Zhang, P.; Song, G.; Li, H.-N.; Lin, Y.-X. Seismic Control of Power Transmission Tower Using Pounding TMD. J. Eng. Mech. 2013, 139, 1395-1406. [CrossRef]

19. Li, T.; Xia, G. Wind-induced vibration control of power transmission tower using pounding tuned mass damper. J. Vibroeng. 2015, 17, 3693-3701.

20. Song, G.B.; Zhang, P.; Li, L.Y.; Singla, M.; Patil, D.; Mo, Y.L. Vibration Control of a Pipeline Structure Using Pounding Tuned Mass Damper. J. Eng. Mech. 2016, 142, 4016031. [CrossRef]

21. Wang, W.; Hua, X.; Wang, X.; Chen, Z.; Song, G. Numerical modeling and experimental study of a novel pounding tuned mass damper. J. Vib. Control 2018, in press. [CrossRef]

22. Li, H.; Zhang, P.; Song, G.; Patil, D.; Mo, Y. Robustness study of the pounding tuned mass damper for vibration control of subsea jumpers. Smart Mater. Struct. 2015, 24, 95001. [CrossRef]

23. Liu, Y.; Yin, X.; Deng, L.; Cai, C. Ride comfort of the bridge-traffic-wind coupled system considering bridge surface deterioration. Wind Struct. 2016, 23, 19-43. [CrossRef]

24. Yin, X.; Fang, Z.; Cai, C.S. Lateral Vibration of High-Pier Bridges under Moving Vehicular Loads. J. Bridge Eng. 2011, 16, 400-412. [CrossRef]

25. Yin, X.; Liu, Y.; Chen, S. Assessment of ride safety based on the wind-traffic-pavement-bridge coupled vibration. Wind Struct. 2017, 24, 287-306. [CrossRef]

26. Yin, X.; Liu, Y.; Song, G.; Mo, Y.L. Suppression of bridge vibration induced by moving vehicles using Pounding Tuned Mass Dampers. J. Bridge Eng. (ASCE) 2018, 23, 04018047. [CrossRef]

27. ISO. Mechanical Vibration and Shock-Evaluation of Human Exposure to Whole Body Vibration-Part1: General Requirements; ISO 2631-1:1997E; ISO: Geneva, Switzerland, 1997.

(C) 2019 by the authors. Licensee MDPI, Basel, Switzerland. This article is an open access article distributed under the terms and conditions of the Creative Commons Attribution (CC BY) license (http:/ / creativecommons.org/licenses/by/4.0/). 